\title{
WILLINGNESS TO PAY FOR INSECTICIDE-TREATED NETS IN BEREHET DISTRICT, AMHARA REGION, NORTHERN ETHIOPIA: IMPLICATION OF SOCIAL MARKETING
}

\author{
Adisu Aleme ${ }^{1}$, Eshetu Girma ${ }^{2}$, Netsanet Fentahun ${ }^{2}$
}

\section{ABSTRACT}

BACKGROUND: Understanding the feasibility of achieving widespread coverage with InsecticideTreated Nets has to be preceded by learning how people value the Insecticide-Treated Nets and estimating the potential demand and willingness to pay so that sustainability of the intervention can be assured. The objective of this study was to determine willingness to pay for Insecticide-Treated Nets among households in Berehet District, Northern Ethiopia.

METHODS: A community-based cross-sectional study was conducted using both quantitative and qualitative methods in five randomly selected Kebeles from January-February 2012. Open ended contingent valuation technique with follow-up method was used. Qualitative data were collected through focus group discussions and observation methods. Binary logistic regression was used to determine the association between dependent and independent variables.

RESULTS: The average number of individuals per Insecticide-Treated Nets was 3.83 .Nearly 68.5\% persons had willingness to buy Insecticide-Treated Nets if they have access to these Nets. The median maximum price a person is willingness to pay for blue rectangular Insecticide-Treated Net was 20 ETB. People had willingness to pay 30 ETB for blue and white conical insecticide-treated nets. Working on knowledge of malaria $(O R=0.68, C I(0.47,0.98 ; p<0.05)$, perceived benefit of Insecticide-Treated Nets $(O R=0.28, C I(0.2-0.4 ; p<0.05)$, perceived susceptibility $(O R=0.64(0.44-0.93 ; p<0.05)$ and perceived severity of malaria $(O R=0.65(0.47-0.91, p<0.05)$ had significant association with a willingness to pay Insecticide-Treated Nets. Respondents who prefer kebele/placel to buy Insecticide-Treated Net for rectangular shape had a significant association with a willingness to pay for Insecticide-Treated Nets $(O R=1.92, C I=1.07-3.92)$.

CONCLUSIONS: Promotions, products, price and place had significant association with willingness to pay for Insecticide-Treated Nets. Designing a social marketing strategy helps ensure sustainable supply of Insecticide-Treated Nets and proper use of Insecticide-Treated Nets.

KEYWORDS: Willingness to pay, Insecticide-Treated Nets, Social marketing, Malaria

\section{DOI: http://dx.doi.org/10.4314/ejhs.v24i1.10}

\section{INTRODUCTION}

Malaria remains a major public health problem causing an unacceptable toll on the health and economic welfare of the world's poorest communities (1). In Ethiopia, the disease has been consistently reported as the first leading cause of outpatient visits, hospitalization and death in health facilities across the country, but now the disease is the six leading cause of morbidity and mortality $(2,3)$.

Insecticide-Treated Nets (ITNs) have been demonstrated significant in reducing morbidity and mortality because of malaria in sub-Saharan

\footnotetext{
${ }^{1}$ Amhara Regional state Health Bureau, Ethiopia

${ }^{2}$ Departments of Health Education and Behavioral Sciences, Jimma University, Jimma, Ethiopia

Corresponding Author: Netsanet Fentahun, P.O. Box 378, Email:_netsanet_fentahun@yahoo.com
} 
Africa. ITN is one of the key malaria control measures in endemic countries in order to reach the Millennium Development Goal which targets to reverse the incidence of malaria by 2015(4). Reports have shown that high ownership and use of ITNs reduces all-cause of under-five mortality by $20 \%$ and malarial infections among under-five children and pregnant women by up to $50 \%$ (5).

Malaria Indicator Survey (MIS) 2007 in Ethiopia confirmed that 4.5 members sharing 1.8 sleeping spaces in household, indicating that the target of supplying each household with two family-sized ITNs should be adequate to attain universal coverage of the household. But, there is a gap in attaining universal coverage of the household (6).

Social marketing is the application of commercial marketing principles to influence human behavior. The aim of social marketing is to sell healthy behavior. The Four P's of Marketing are: Product represents the desired behavior you are asking your audience to do, and the associated benefits, tangible objects, and/or services that support behavior change. The second $\mathrm{P}$ represents price, in this study we only focus on financial costs. The third $\mathrm{P}$, place, is where the audience will perform the desired behavior; where they will access the program products and services. The last $\mathrm{P}$, promotion, stands for communication messages, materials, channels, and activities that will effectively reach the audience (7).

Social marketing is becoming an increasingly popular method of ITN distribution in Africa, with nets and insecticides being made available for purchase at lower-than-market costs through subsidies provided either by other consumers or external donors (8). Willingness to pay (WTP) and consumer preferences are very important for introducing ITN in the market for sale rather than for free distribution. This helps ensure sustainability and self-reliance in the prevention of malaria. This implies that people value more paid ITNs than freely distributed ones (9).

Proponents of cost-sharing ITN distribution programmes argue that charging an affordable price is needed to screen out people who will not use the net, and thus avoid wasting the subsidy on non-users $(10,11)$. Raising prices too high will deny services to poor clients. However, maintaining low prices will perpetuate reliance on external donors. Although cost-sharing may lead to higher usage intensity, it may also reduce programme coverage by dampening demand (12). In WTP, estimates are sensitive to client characteristics such as motivation to use the product or service or socioeconomic status (SES) (13-16). Apart from individuals' social and economic background, characteristics of products to be purchased have a great impact on WTP (11$21)$. Payment scenario is also one of the central predictors that studies have identified for WTP for ITNs $(12,14,20-22)$. $(14,16,22-24)$.

The current policy of the Ethiopian Government favors free distribution of ITNs. But, the country faces problem on universal coverage and sustainability of ITN in the household level. Currently, there is a shortage of ITNs supply in Ethiopia due to funding dependency. To solve this setback, it is better to understanding the factors that are associated with individuals and characteristics of ITNs in order to establish effective social marketing strategies within the general population. The purpose of this study was thus to determine the willingness to pay for ITN and the associated factors in Berehet District, Northern Ethiopia.

\section{METHODS AND MATERIALS}

A Community-based cross-sectional study design using both quantitative and qualitative research methods was employed. The study was conducted in Berehet District from January to February 2012. According to the 2010 projections, the total population of the district is around 37,182 (18,219 females and 18,967 males). The district is divided into one urban and nine rural kebeles (the smallest administrative units). Nine kebeles were malaria endemic. A total of 5316 households were found in malarious kebeles.

The study was conducted on 790 households. The sample size was determined using single population proportion formula by assuming $(\mathrm{P}=$ 0.51 ; households who were willing to pay a rectangular ITN at price of 20 Birr) (14), confidence level $=95 \%$, margin of error $=5 \%$ with correction formula, design effect $=2$ and non-response rate $=10 \%$ ). The heads of households or representatives were included in the study. If the household head was absent, a person of 18 years and above was interviewed.

Out of the nine kebeles, five clusters were selected by simple random sampling technique. Households were sampled from each cluster. 
Households were selected through simple random sampling technique using the recent registration list which was obtained from the District Health Office. Three Focus Group Discussions were conducted. Household heads, women who had under-five children and key informants or kebele leaders were included in the Focus Group Discussions. The study participants were selected with the help of kebele leaders and health extension workers.

A face-to-face interviewer administered questionnaire was used to collect data. The questionnaire was adapted from pervious similar studies $(14,17)$. The questionnaire has three parts; the first part contains nine items of sociodemographics. The second part is social marketing: promotion (knowledge of malaria (twelve items), perceived threats of malaria and perceived benefit of ITNs (five items for each), for ownership of ITN (seven items)); product (the size, shape and colour (eight items)); price/financial cost only: economic capacity/financial power to buy ITNs and commitment of the community/commitment to purchase ITNs (market price, supply, demand, time of payment, ways of payment)((eight items)), and place-where to avail the product/ITNs (Market place, kebeles, health institutions). The third part of includes willingness to pay/outcome variable (fourteen items) using open-ended question with follow-up of contingent valuation methods.

The FGDs were conducted by one trained moderator who had master's degree, a note-taker and assistant who had bachelor degree. The major discussion topics were perceived benefit of ITN, perception towards WTP for ITNs, the kinds of size, shape, and color they know and their willingness to buy for a stated kind of ITNs. Observation was conducted to identify the size, shape, colour, number and ownership of ITN and housing structure. The observation was conducted in all sampled households. An audio tape recorder was used after getting permission from the discussants. Notes were also taken.

For every respondent, one rectangular ITN, which was being freely distributed from government and one white and blue conical (not free) ITN were prepared for demonstration in order to elicit their preferences. Five data collectors (nurses), five supervisors (nurses) were recruited. Both the data collectors and supervisors were trained.

The data were checked and edited before being entered into Epi data version 3.1. After the data were entered, they were exported to SPSS version 16 software for analysis. First, descriptive analysis was done to describe the characteristics of the study participants. And then, bivariate logistic regression analysis was performed. Finally, multiple logistic regression was performed to identify the independent predictors of willingness to pay for Insecticide-Treated Nets (p-value $<0.05)$. The FGDs data were transcribed and manually coded. Finally, themes were triangulated with the quantitative finding.

Ethical clearance was obtained from Jimma University, College of Public Health and Medical Sciences Ethical Review Committee. Written consent was also obtained from each study participant.

\section{RESULTS}

Socio-demographic characteristics of the respondents: Out of 790 study participants, 746 household heads or representatives were interviewed resulting the response rate of $94.4 \%$. From the total household heads, 424 (56.8\%) were males. The minimum age was 18 years and the maximum was 85 years (median age $=33.2110 .89$ years). Three hundred and eighty-five (51.6\%) household heads were illiterate. The average family size per household was $4.28 \pm$ SD 2.2. The median monthly income was 400 ETB $( \pm$ SD 504) (Table 1).

Knowledge of malaria: Seven hundred and four individuals $(96.6 \%)$ reported that malaria is caused by the bite of malaria-causing mosquitoes. Regarding knowledge on prevention of malaria, $85 \%, 68.9 \%, 56.6 \%, 47.9 \%$ of the respondents respectively mentioned ITN utilization, environmental sanitation, insecticide spray, and taking anti-malaria medication as the commonest methods of prevention. Almost half $(50.6 \%)$ of the respondents had knowledge on cause, prevention and transmission of malaria. 
Table 1 : Socio-demographic status of households in Berehet District, Ethiopia, 2012.

\begin{tabular}{ll}
\hline Variables (n=746) & Number $(\%)$ \\
\hline Residence & \\
Rural & $505(67.7)$ \\
Urban & $241(32.3)$ \\
Gender & $424(56.8)$ \\
Male & $322(43.2)$ \\
Female & \\
Marital Status & $547(73.3)$ \\
Married & $88(11.9)$ \\
Single & $74(9.9)$ \\
Divorced & $36(4.8)$ \\
Widowed & \\
Religion & $486(65.1)$ \\
Orthodox & $248(33.2)$ \\
Muslim & $12(1.6)$ \\
Protestant & \\
Educational status & $385(51.6)$ \\
Could not read and write & $189(25.3)$ \\
Read and write only & $67(9.0)$ \\
Elementary (1-8 grades) & $37(5.0)$ \\
Secondary(9-12 grades) & $68(9.1)$ \\
College and above & \\
Ethnicity & $617(82.7)$ \\
Amhara & $7(0.9)$ \\
Oromo & $121(16.3)$ \\
Others (Aregoba ,Kemebata, Tigre) & \\
Occupation & $430(57.6)$ \\
Farmer & $77(10.3)$ \\
Merchant & $79(10.6)$ \\
House wife & $160(21.4)$ \\
Others (daily labor, student, teacher and contractor) & \\
Family size & $419(56.2)$ \\
44 & $213(28.6)$ \\
>6 & $114(15.3)$ \\
Household possession & \\
Telephone & $375(50.3)$ \\
Functional radio & $336(44.2)$ \\
Electricity & $220(29.5)$ \\
Television & $63(8.4)$ \\
Average family monthly income & $186(24.9)$ \\
<200 & \\
201-400 & \\
$>692$ & \\
\hline & \\
\hline
\end{tabular}

Perception of malaria and source of information: Four hundred and six $(55.7 \%)$ respondents perceived that under-five children are high risk group. Similarly, $135(18.5 \%)$ of the respondents perceived pregnant women as one of the high risk group for malaria infection. $75.4 \%, 51.07 \%$ and $54.6 \%$ of the respondents had high perceived susceptibility and severity to malaria and high perceived benefit to ITNs Respectively. (Table 2) 
Table 2 : knowledge of the respondents on malaria in Berehet District, Ethiopia, 2012.

\begin{tabular}{|c|c|}
\hline Variables & Number $(\%)$ \\
\hline \multicolumn{2}{|l|}{ Ever heard of malaria $(\mathrm{N}=746)$} \\
\hline Yes & $729(97.7)$ \\
\hline No & $18(2.3)$ \\
\hline \multicolumn{2}{|l|}{ Source of information about malaria $(n=729$} \\
\hline health workers & $668(91.6$ \\
\hline Community events & $454(62.3)$ \\
\hline Parents & $304(41.7)$ \\
\hline Radio & $290(39.9)$ \\
\hline Friends & $231(31.7)$ \\
\hline Schools & $112(15.4)$ \\
\hline Television & $98(13.4)$ \\
\hline Newspaper & $67(9.2)$ \\
\hline leaflets/poster & $63(8.7)$ \\
\hline \multicolumn{2}{|l|}{ Perceived cause of malaria $(\mathrm{N}=729$ ) } \\
\hline Mosquito bite & 704 (96.6) \\
\hline Hunger & $167(22.9)$ \\
\hline Cold weather & $114(15.6)$ \\
\hline Lack of personal hygiene & $71(9.7)$ \\
\hline Others (stagnant water, sleeping in river) & 47 (6.4) \\
\hline Contact with malaria patient & $36(4.8)$ \\
\hline \multicolumn{2}{|c|}{ Common symptoms of malaria mentioned $(n=729)$} \\
\hline Fever & $679(93.1)$ \\
\hline Chills & $633(86.8)$ \\
\hline Headache & $537(73.7)$ \\
\hline Vomiting & $344(47.2)$ \\
\hline Body weakness & $342(46.9)$ \\
\hline Sweating & $320(43.9)$ \\
\hline Thirsty & $289(39.6)$ \\
\hline Loss of appetite & $288(39.5)$ \\
\hline Joint pain & $7(1)$ \\
\hline \multicolumn{2}{|l|}{ Is malaria communicable disease $(n=729)$} \\
\hline No & $466(63.8)$ \\
\hline Yes & $264(36.2)$ \\
\hline \multicolumn{2}{|c|}{ Reported mode of transmission of malaria $(n=264)$} \\
\hline Mosquito bite & $252(95.5)$ \\
\hline Contact with a malaria patient & $22(8.3)$ \\
\hline Due to cold & 19(7.2) \\
\hline By flies & $8(95.5)$ \\
\hline \multicolumn{2}{|c|}{ Perceived malaria prevention methods $(\mathrm{n}=729)$} \\
\hline ITN s utilization & $620(85)$ \\
\hline Environmental sanitation & $502(68.9)$ \\
\hline Insecticide spray & 414 (56.6) \\
\hline Taking anti malaria medication & $346(47.5)$ \\
\hline Others* & $57(7.8)$ \\
\hline \multicolumn{2}{|l|}{ Perceived risk groups to malaria $(n=729)$} \\
\hline Under five children & $406(55.7)$ \\
\hline Pregnant women & $135(18.5)$ \\
\hline Anyone & $89(12.2)$ \\
\hline Youths & $52(7.1)$ \\
\hline Adults & 47 (6.4) \\
\hline
\end{tabular}

*Avoiding stagnant water, not sleeping in river area 
Condition on ownership of Insecticide Treated Bed Net and housing structure: Five hundred and forty $(72.4 \%)$ respondents had one bed during the data collection period. Among these, 465 (62.6\%) households had rectangular Insecticide Treated Bed Net during observation. The average number of ITNs per household was 1.01 with $\mathrm{SD} \pm 0.1$. On average, the number of sleeping places per household was 1.75 with $\mathrm{SD} \pm 0.68$.

Product: Four hundred and sixty-five $(62.6 \%)$ households had rectangular ITNs during observation. Two hundred and seventy two $(53.2 \%)$ respondents preferred to have conical types of ITNs, while 239 (46.8\%) preferred rectangular ITNs. The reason why the people chose rectangular ITNs and conical types was easy: to hang in their housing structure, similar shape with their sleeping place/bed, and attractiveness. Blue color and medium size were the most preferred colour and size respectively. A 40 years-old male said, "I know a two-meter length of rectangular ITN that I obtained from health post, and it is easy to hang around my sleeping place."

Place: Nearly half (47\%) of the respondents preferred to buy ITNs from health centers while $34.8 \%$ respondents also preferred to buy from health posts.

Price: Out of 540 families who owned ITNs, around $526(97.4 \%)$ obtained their ITNs for free. Four hundred and one $(78.5 \%)$ respondents wanted to pay for nets. As the price of ITN increases, the respondents' willingness to pay for this item decreases regardless of the shape, type and color of the nets. One hundred and sixty three $(31.9 \%)$ respondents preferred the fall (September-November) season of the year, and the most preferred time of the day was mooring $272(53.2 \%)$ (Table 3).

Willingness to pay for ITNs: Seven hundred (93.8\%) respondents decide to use ITNs soon. From the total of 746 respondents, 511 (68.5\%) were willing to buy ITNs if available in the market and the rest of $235(31.5 \%)$ were not willing to buy at any price. A 38 years-old female said, "ITN has been freely distributed from health posts and kebeles in order to prevent malaria and other diseases. This government-free distribution may not continue for the future like other services. I think the best solution in order to ensure sustainable supply of ITN for my family is buying
ITN if it is available in the market at reasonable prices."

The median price that the respondents were willing to pay for freely distributed rectangular ITNs was initially 20 ETB with minimum 5 and maximum 100 ETB. About half (53.8\%) of the respondents were willing to buy it if this price was increased by $50 \%$. The median maximum price that respondents were willing to pay for this ITN was 20 ETB with minimum 5 and maximum 150 ETB. A 46 years-old female said, "If rectangular ITN is available in the market, I can buy it for 3050 Birr for me and the rest of my family."

Regarding blue conical ITNs, the median price that respondents were willing to pay was initially at 20 ETB with a minimum of 5 and maximum of 200 ETB. More than half $(56 \%)$ of the respondents were willing to buy it if this price was increased by $50 \%$. The median maximum amount that respondents were willing to pay for this type of ITN was $30 \mathrm{ETB}$ with a minimum o 5 and maximum of $250 \mathrm{ETB}$.

The median price that respondents were willing to pay for white conical ITN was 20 ETB with minimum 5 and maximum 200 ETB. On the other hand, $269(52.6 \%)$ respondents were willing to buy this type of ITN if this price was increased by $50 \%$. The median maximum amount that respondents were willing to pay for this ITN was 30 ETB (with a minimum of 5 and a maximum of 250 ETB.

Factors affecting willingness to pay for ITNs: Logistic regression analysis was done to identify the effect of independent variables on willingness to pay for ITN. Females showed a higher willingness to pay for ITN than males (AOR=1.86, CI= 1.29, 2.55). Respondents who were married, widowed and divorced had higher willingness to pay for ITNs. Respondents who completed primary school had higher WTP for ITNs (AOR-4.72, 95\% CI =1.48-15.04). As the average monthly income of respondents decreased, the WTP for ITNs had increased significantly (AOR-22.44, 95\% CI =12-41.34).

Respondents who had poor knowledge about malaria had less WTP for ITNs than respondents who had knowledge (AOR-0.68, 95\% CI $=0.47$ 0.98). Respondents who showed low perceived benefit of ITNs (AOR-0.28, 95\% CI $=0.2-0.4$ ), low perceived susceptibility (AOR-0.64, 95\% CI $=0.44-0.93)$ and low severity $($ AOR- $-0.65,95 \%$ CI 
$=0.47-0.91)$ of malaria had significantly lower perceived susceptibility and severity respectively WTP for ITNs than higher perceived benefit, (Table 4).

Table 3: Preference and WTP for ITNs in Berehet District, Ethiopia, 2012

\begin{tabular}{|c|c|}
\hline Variables & Number $(\%)$ \\
\hline \multicolumn{2}{|c|}{ preferred shape of ITNs to purchase $(n=511)$} \\
\hline Conical & $272(53.2)$ \\
\hline Rectangular & $239(46.8)$ \\
\hline \multicolumn{2}{|c|}{ Preferred color for Rectangular ITNs $(n=239)$} \\
\hline Blue & $204(85.4)$ \\
\hline Green & $18(7.5)$ \\
\hline White & $17(7.1)$ \\
\hline \multicolumn{2}{|c|}{ Preferred size for Rectangular ITNs $(n=239)$} \\
\hline Medium size & $144(60.3)$ \\
\hline Large size & $91(38.1)$ \\
\hline Small size & $4(1.7)$ \\
\hline \multicolumn{2}{|c|}{ Preferred color for Conical ITNs $(n=272)$} \\
\hline Blue & $199(73.2)$ \\
\hline White & $59(21.7)$ \\
\hline Green & $14(5.1)$ \\
\hline \multicolumn{2}{|c|}{ Preferred size for Conical ITNs ( $\mathrm{n}=272$ ) } \\
\hline Medium size & $200(73.5)$ \\
\hline Large size & $65(23.9)$ \\
\hline Small size & $7(2.6)$ \\
\hline \multicolumn{2}{|c|}{ Initial WTP for rectangular ITN } \\
\hline$<10$ Birr & $204(39.9)$ \\
\hline 10-25 Birr & $192(37.6)$ \\
\hline$>25$ Birr & $115(22.5)$ \\
\hline \multicolumn{2}{|c|}{ Maximum WTP for rectangular ITN } \\
\hline$<15$ Birr & $200(39.1)$ \\
\hline 15-31 Birr & $183(35.8)$ \\
\hline$>31$ Birr & $128(25)$ \\
\hline \multicolumn{2}{|c|}{ Initial WTP for blue circular ITN } \\
\hline$<15$ Birr & $128(25)$ \\
\hline 15-30 Birr & $260(50.9)$ \\
\hline > 30 Birr & $123(24.1)$ \\
\hline \multicolumn{2}{|c|}{ Maximum WTP for blue circular ITN } \\
\hline$<20$ Birr & $150(29.4)$ \\
\hline 20-50 Birr & $274(53.6)$ \\
\hline$>50$ Birr & $87(17)$ \\
\hline \multicolumn{2}{|c|}{ Initial WTP for white circular ITN } \\
\hline$<15$ Birr & $135(26.4)$ \\
\hline 15-30 Birr & $254(49.7)$ \\
\hline > 30 Birr & $122(23.9)$ \\
\hline \multicolumn{2}{|c|}{ Maximum WTP for white circular ITN } \\
\hline$<20$ Birr & $159(31.1)$ \\
\hline 20-45 Birr & $229(44.8)$ \\
\hline$>45$ Birr & $123(24.1)$ \\
\hline
\end{tabular}


Table 4: Factors for willingness to pay for ITNs in Berehet District, Ethiopia, 2012

\begin{tabular}{|c|c|c|c|c|}
\hline \multirow[t]{2}{*}{ Variables } & \multicolumn{2}{|c|}{ Willingness to pay for ITNs } & \multirow[t]{2}{*}{$\operatorname{COR}(95 \% \mathrm{CI})$} & \multirow[t]{2}{*}{$\operatorname{AOR}(95 \% \mathrm{CI})$} \\
\hline & No $(\%)$ & Yes $(\%)$ & & \\
\hline \multicolumn{5}{|l|}{ Gender } \\
\hline Males & $103(24.3)$ & $321(75.7)$ & 1.00 & 1.00 \\
\hline Female & $132(41)$ & 190(59) & $2.16(1.58-2.96)^{*}$ & $1.86(1.29-2.55) *$ \\
\hline \multicolumn{5}{|l|}{ Marital Status } \\
\hline Single & $16(17.8)$ & $73(82)$ & 1.00 & 1.00 \\
\hline Married & 165(31.2) & $382(68.8)$ & $1.97(1.11-3.48) *$ & $1.96(1.07-3.38) *$ \\
\hline Widowed & $17(47.3)$ & $19(52.7)$ & $4.08(1.74-9.54) *$ & $2.92(1.22-6.96) *$ \\
\hline Divorced & $37(50)$ & $37(50)$ & $4.56(2.24-9.25) *$ & $3.26(1.56-6.97) *$ \\
\hline \multicolumn{5}{|l|}{ Educational status } \\
\hline Illiterate & 158(41.1) & 227(58.9) & 1.00 & 1.00 \\
\hline Can read and write & $47(24.9)$ & $142(75.1)$ & $0.47(0.32-0.7)^{*}$ & $0.61(0.39-0.93) *$ \\
\hline Elementary $(1-8)$ & $17(25.4)$ & $50(74.6)$ & $0.49(0.27-0.87)^{*}$ & $4.72(1.48-15.04) *$ \\
\hline Secondary $(9-12)$ & $9(24.4)$ & $28(75.6)$ & $0.46(0.21-1.00)$ & $0.43(0.18-1.03)$ \\
\hline College and above & $4(5.9)$ & $64(94.1)$ & $0.09(0.03-0.25)^{*}$ & $0.99(0.29-0.99)^{*}$ \\
\hline \multicolumn{5}{|c|}{ Average family monthly income } \\
\hline$<200$ & $146(75.3)$ & $48(24.7)$ & $30.23(16.66-54.89) *$ & $22.44(12-41.34) *$ \\
\hline $201-400$ & $56(30.7)$ & 127(69.3) & $4.38(2.43-7.9) *$ & $3.01(1.64-5.52) *$ \\
\hline $401-692$ & $16(8.8)$ & 167(91.2) & $0.95(0.46-1.84)$ & $0.67(0.32-1.39)$ \\
\hline$>692$ & $17(9.2)$ & $169(90.8)$ & 1.00 & 1.00 \\
\hline \multicolumn{5}{|c|}{ Knowledge on malaria } \\
\hline knowledgeable & $97(25.6)$ & 281(74.3) & 1.00 & 1.00 \\
\hline Not knowledgeable & $128(36.5)$ & $223(63.5)$ & $0.60(0,43-0.82) *$ & $0.68(0.47-0.98) *$ \\
\hline \multicolumn{5}{|c|}{ Perceived susceptibility of malaria } \\
\hline High & $133(23.6)$ & $430(76.4)$ & 1.00 & 1.00 \\
\hline Low & $67(40.4)$ & $99(59.6)$ & $0.63(0.44-0.91) *$ & $0.64(0.44-0.93) *$ \\
\hline \multicolumn{5}{|c|}{ Perceived severity of malaria } \\
\hline High & $178(46.7)$ & 203(53.3) & 1.00 & 1.00 \\
\hline Low & $200(57.5)$ & $148(42.5)$ & $0.63(0.46-0.87) *$ & $0.65(0.47-0.91) *$ \\
\hline \multicolumn{5}{|c|}{ Perceived benefit for ITNS } \\
\hline High & $167(41)$ & 241(59) & 1.00 & 1.00 \\
\hline Low & $102(31.8)$ & $219(68.2)$ & $0.26(0.19-0.36) *$ & $0.28(0.2-0.4) *$ \\
\hline
\end{tabular}

* Statically significant at p-value $<0.05$

Regarding respondents' tendencies to buy ITNs, those who prefer kebele in order to buy rectangular shape were more likely to buy than other places $[\mathrm{OR}=1.92, \mathrm{CI}=1.07-3.92]$. And those who prefer kebele for circular shape were less likely to buy than other places $[\mathrm{OR}=0.41, \mathrm{CI}=$ $0.43-0.911]$. Respondents who were willing to pay for ITNs through cash were less willing to pay rectangular ITNs than loan basis $[\mathrm{OR}=0.35, \mathrm{CI}=$ 24-0.741]. Respondents who had willing to pay for ITNs in cash had higher willingness to pay circular ITNs than of loan basis.

\section{DISCUSSION}

The cross-sectional nature of the study might have masked the relationship between some variables and some outcomes. With this limitation, we tried to discuss the finding of this study. The findings of this study show that there was high awareness about malaria among the respondents. This finding is very similar with that of a study conducted in Uganda (25). The reason might be the contribution of health extension programme in study area. This finding is similar with the finding of a study conducted in other parts of Ethiopia $(19,23,25)$. Households ITNs coverage was lower than the target national ITNs coverage. This finding is very low in terms of Households ITNs coverage as 
compare to the national strategies $(3,6)$. The possible reason might be scarcity of logistics or under-planning during the programme design stage. Hence, why the national target coverage was not achieved needs further investigation.

A significant proportion of participants preferred to buy conical type of ITNs than rectangular ones, and the most preferred color was blue for both conical and rectangular ITNs. These findings are similar with those of studies conducted in the Peruvian Amazon and in rural Tanzania (17, 26). These finding are also supported by the qualitative finding in this study.

The majority of the respondents preferred to obtain ITNs from health centers on loan basis during fall season. This finding is similar with those of studies conducted in four regions of Ethiopia and the Peruvian Amazon $(23,17)$. This is also supported by the results of the focus group discussion. The possible reason may be related to high credibility of health centers by the community or previous association of ITNs and the health centers. Fall season was preferred may be because people could sell their agricultural products after the harvest season, have more purchasing power during this time of the year, or it can be because of the fact that awareness of the respondents about malaria becomes the highest during this seasons of the year.

The majority of the respondents were willing to buy ITNs if there is availability in the market with reasonable price. It is known that costsharing, a popular approach for supporting and sustaining health services in less developed countries, and WTP studies are considered a simple, quick and cheap approach to evaluate their potential revenue and demand (27). In addition, studies in other African countries and Ethiopia indicated that household members were willing to pay for ITNs $(16,24,28)$.

The respondents who can read and write and those with college and above education were less likely to have WTP than respondents who were illiterate $(19,22)$. This may be due to a high risk perception among the less educated on malaria. In this study, females showed higher WTP for ITNs than males. But, other studies showed that females were less likely to be more willing than males to pay for ITNs $(19,26)$. The difference might be attributed to health extension programme in the study area.
According to a previous study, favorable beliefs were important in predicting willingness to pay for ITNs (29). In this study, too, respondents who had high perceived benefit of ITNs were more likely to have WTP. In addition, other cognitive factors which were predictors of WTP for ITNs that included respondents with high knowledge level, perceived severity and susceptibility on malaria were found to be significantly associated with willingness to pay. This finding is similar with studies conducted in Nigeria and Ethiopia (14, 16). These cognitive factors were higher in the present study, may be, because health extension workers were among the closest sources of information.

From this study, we can conclude that the number of individuals per ITN was lower than the national target. A significant number of respondents had willingness to pay for ITN. Promotion, place and price were predictors of willingness to pay for ITNs, while product was not. Designing ITNs with social marketing strategy can help to ensure sustainable supply and proper use of ITNs.

\section{ACKNOWLEDGMENTS}

We would like to extend our thanks to the Department of Health Education and Behavioral Sciences, College of Public Health and Medical Sciences with Jimma University for the financial and technical supports. We also convey our special thanks to Debre-Berhan Zonal Health Office, Berehet District Health Office, data collectors, supervisors and study participants.

\section{REFERENCES}

1. World Health Organization, United Nation Children's Fund and Roll Back Malaria. World malaria report. Geneva, 2005: 1-34.

2. Melanie B, Clifford M, Randall K. Current Policy and Status of DDT Use for Malaria Control in Ethiopia, Uganda, Kenya and South Africa, 2007: $1-23$.

3. FMOH. National five years strategic plan for malaria prevention and control in Ethiopia in Addis Ababa, 2006:1-48.

4. WHO. WHO Global Malaria Programme: World malaria report, 2010:1-48.

5. Federal democratic republic of Ethiopia. MDGs report. Addis Abeba, 2010:1-37. 
6. Daddi J, Asfaw G, Hana B, Richard S, Paul E, Patricia G, Teshome G, Richard R, Jimee H. Malaria indicator survey 2007 in Ethiopia: coverage and use of major malaria prevention and control interventions. Malar J, 2010; 9:58.

7. Turning Point Social Marketing National Excellence Collaborative. The Basics of Social Marketing: How to Use Marketing to Change Behavior. Third in a series of Turning Point resources on social marketing, 1997.

8. Carol B. why some nets owned are not used, bed net utilization study, United States Agency for International Development Net Mark a project, 2007: 1-25.

9. Don M, Carl C, Terrie T, Robin B, Mark W. Socially marketed insecticide-treated nets effectively reduce Plasmodium infection and anemia among children in urban Malawi. Tropical Medicine and International Health, 2006; 11:1367-1374.

10. Alexis R. Best practices for an insecticide-treated bed net distribution programme in sub-Saharan eastern Africa. Sexton Malaria Journal, 2011; 10:1-10.

11. Jessica C, pascaline D. Free distribution or costsharing? Evidence from a randomized malaria prevention experiment. Quarterly Journal of Economics, 2010; 125: 1-45.

12. Alison W, Kevn S. Willingness to pay surveys a streamlined approach: Guideline for small town water supply. Lough Borough University, 2003: 1-248.

13. Claire C, Elisa S, Charfudin S, Delino N, Ariel N, Pedro A, Clara M. Determinants of household demand for bed nets in a rural area of southern Mozambique. Malaria Journal, 2009; 8:1-13.

14. Obinna O, Kara H, Julia F. Inequalities in purchase of mosquito nets and willingness to pay for insecticide-treated nets in Nigeria: Challenges for malaria control interventions. Malaria Journal, 2004; 3:1-8.

15. Mujinja G, Makwaya K, Sauerborn R. Gender and willingness to pay for ITN in a poor rural area in Tanzania. East African medical journal, 2004; 18: 641-647.

16. Frehywot E, Damen H. Factors Influencing People's Willingness-to-buy Insecticide-treated Bed nets in Arbaminch Zuria District, Southern Ethiopia. J health population nutrition, 2011; 29: 200-206.

17. Steven H, Maribel O, Elli L, Clara P, Luz Marina $\mathrm{P}$, Peter W. The whole world will be able to see us: determining the characteristics of a culturally appropriate bed net among mestizo communities of the Peruvian Amazon. The American journal of tropical medicine and hygiene, 2008; 79:834-8.
18. Carol B, Richard R, Sara W. Factors associated with use and non-use of mosquito nets owned in Oromia and Amhara Regional States, Ethiopia. Malaria Journal, 2009; 8:1-11.

19. Getachew S. Assessment of use of insecticide treated bed net and factors affecting it in Serbo town, Jimma zone. AAU, Medical Faculty Public health department, 2005: 55-57.

20. Eija p. Attitude-behavior framework in contingent valuation of forest conservation university of Helsinki department of forest economics. $J$ health eco, 2003:1-22.

21. Alessandro T, Aprajit M, Brian D, Lakshmi K, Joanne Y. Micro-loans Insecticide-Treated Bed nets and Malaria: Evidence from a randomized controlled trial in Orissa. SSRN, 2011; 11: 1-23.

22. Obinna O, Benjamin U. Stated and actual altruistic willingness to pay for insecticide treated nets in Nigeria: validity of open-ended and binary with follow-up questions. Health Econ, 2004; 13:477-492.

23. Daddi J, Gezahegn T, Wakgari D, Adugna W, Daniel K, Desta A. Baseline survey for the implementation of ITN in malaria control in Ethiopia. Ethiop J Health Dev, 2005; 19:17-22.

24. Musa I, Salaudeen A, Jimoh O. Awareness and use of Insecticide Treated Nets among women attending ante-natal clinic in a Northern state of Nigeria. J Pak Med Assoc, 2009; 59:354-8.

25. Nuwaha F. Factors affecting the use of mosquito nets in Mbarara municipality of western Uganda. American Journal of Tropical Medicine and Hygiene, 2001; 65: 877-882.

26. Phare G, Mujinja M. Exploring determinants of consumer preferences and willingness-to-pay for insecticides treated bed nets before intervention in a poor rural Tanzania. East African Journal of Public Heath, 2006; 3:17-23.

27. Russell S, Fox-Rushby J, Arhin D. Willingness and ability to pay for health care: a selection of methods and issues. Health Policy and Planning, 1995; 10:94-101.

28. Mugisha F, Arinaitwe J. Sleeping arrangement and mosquito net use among under-fives, results from the Ugandan demographic and health survey. Malaria Journal, 2003; 2:40-4.

29. Marchant T, Schellenberg A, Edgar T, Nathan R, Abdulla S, Mukasa O, Mponda H, Lengeler C. Socially marketed insecticide-treated nets improve malaria and anemia in pregnancy in southern Tanzania. Trop Med Int Health, 2002; 7:149-58. 